\title{
Baumeister, Martin, Kriegstheater. Großstadt, Front und Massenkultur 1914-1918
}

\section{Nicolas Beaupré}

\section{OpenEdition}

\section{Journals}

Édition électronique

URL : http://journals.openedition.org/ifha/1712

DOI : 10.4000/ifha.1712

ISSN : 2198-8943

Éditeur

IFRA - Institut franco-allemand (sciences historiques et sociales)

Référence électronique

Nicolas Beaupré, «Baumeister, Martin, Kriegstheater. Großstadt, Front und Massenkultur 1914-1918», Revue de I'IFHA [En ligne], Date de recension, mis en ligne le 01 janvier 2008, consulté le 22 septembre 2020. URL : http://journals.openedition.org/ifha/1712 ; DOI : https://doi.org/10.4000/ifha.1712

Ce document a été généré automatiquement le 22 septembre 2020

(CIFHA 


\title{
Baumeister, Martin, Kriegstheater. Großstadt, Front und Massenkultur
}

\section{4-1918}

\author{
Nicolas Beaupré
}

Si les liens entre la Grande Guerre et la littérature, sous l'angle le plus souvent de la question du témoignage, font l'objet d'études toujours plus nombreuses et donnent lieu à bien des débats, le théatre entre 1914 et 1918 reste un thème encore curieusement peu étudié. L'étude de M.B. consacrée au cas allemand vient donc combler un vide. Issu d'une thèse d'habilitation, l'ouvrage étudie la question à la fois chronologiquement et dans une triple perspective plus thématique : celle des circulations des représentations de la guerre sur la scène, celle de la place du théâtre dans les cultures de masse mobilisées, pour se pencher enfin sur le théatre aux armées. Comme l'auteur le souligne, le prisme du théâtre a également l'avantage de permettre d'étudier à la fois la culture des élites et la culture populaire. Les spectacles populaires et/ou de divertissement qui s'étaient multipliés à Berlin dans la seconde moitié du XIXe s. sont d'ailleurs au centre de cet ouvrage.

Le premier mérite de cette étude est donc de tenter de rendre compte du théâtre comme un phénomène social et artistique total qui traverse aussi bien le Heimatfront que le Front. Seule cette démarche permet à la fois de comparer le théâtre destiné aux masses de l'arrière et celui destiné aux combattants ou pratiqué par eux, mais aussi de mettre en valeur les circulations entre ces deux espaces de la représentation théâtrale. L'ouvrage comporte donc logiquement deux grandes parties. La première, qui représente les deux tiers de l'ouvrage, est consacrée essentiellement à Berlin comme double capitale : de l'art théâtral et du Reich en guerre. Dans la seconde, l'auteur se penche plus spécifiquement sur le théâtre aux armées.

L'entrée en guerre a une triple conséquence sur le monde du théâtre berlinois : la mobilisation le désorganise profondément et les autorités policières et militaires accroissent le contrôle des spectacles représentés notamment dans le domaine du théâtre de divertissement (comique, variété, cabaret). Cependant, le milieu théâtral 
participe de son côté très rapidement à la mobilisation intellectuelle et prend sa part dans la diffusion des " idées de 1914 », des images de l'ennemi et dans la création d'une communauté nationale en guerre : les théâtres ouvrent très vite leurs portes à des soirées et des conférences patriotiques. Les programmes de la première saison de guerre, et ce, aussi bien dans les théâtres prestigieux que dans les théâtres populaires, jusqu'à l'opérette - qui est le genre qui rencontre le plus de succès à Berlin pendant la guerre - et au cirque sont également très marqués par l'actualité guerrière et par l'atmosphère patriotique même si certains directeurs entendent « dépolitiser » le choix des pièces à jouer. Les soldats, les rapports hommes/femmes en guerre, la situation des populations à la guerre, la guerre sous-marine, etc. font leur apparition sur la scène des théâtres.

Cette tendance générale à la mobilisation et à l'auto-mobilisation - à tel point qu'on peut parler de Heimatfronttheater - se maintient majoritairement jusque 1917. L'exemple de l'ascension du chansonnier Otto Reutter est de ce point de vue très parlant : il devient directeur de théâtre et triomphe avec des revues et des opérettes très réactives à l'actualité politique et militaire tout en répondant, au moins jusque 1917, à la fois aux attentes du public et des instances de la propagande et de la censure. Après cette date cependant, les tensions politiques et les divisions idéologiques commencent à avoir des répercussions sur le monde du théâtre. Cependant, l'échec des pièces trop explicitement chauvines à partir de 1917 ne signifia pas pour autant la fin de la représentation de la guerre au théâtre, ni celle de l'expression du patriotisme par d'autres moyens. Celle-ci se manifesta principalement de deux manières différentes et complémentaires, par la multiplication des effets spéciaux d'une part et par la consécration du combattant des tranchées comme personnage de théatre d'autre part. En premier lieu, des spectacles extraordinaires faisant appel à des effets spéciaux se rapprochant du cinéma continuaient de s'attirer les faveurs du public, comme par exemple un spectacle de l'année 1916 qui mettait en scène un sous-marin coulant par le fond des navires ennemis. Le cirque fut aussi l'un des lieux privilégiés de la représentation de la guerre qui allait également dans une direction toujours plus spectaculaire. M. Baumeister développe ici l'exemple du Cirque Sarrasani et de son directeur Hans Stosch prônant des spectacles toujours plus grandioses et divertissants. Mais ce dernier a beaucoup de mal à faire accepter ce type de manifestation par des autorités très méfiantes à l'égard du spectacle populaire et de distraction pure que semble être le cirque. Pourtant, ses spectacles sont également patriotiques, ce que l'autorité militaire ne comprend que très - trop - tardivement pour exploiter les succès de Stosch.

Parallèlement à cette tendance, une pièce écrite par un caporal de la Landwehr mettant en scène le simple combattant remporta un grand succès (Der feldgraue Hias) remporta un immense succès à partir de mars 1916, d'abord en Bavière puis bientôt dans toute l'Allemagne jusqu'en Autriche et ce quasiment jusqu'à la fin de la guerre. La pièce rompait avec le chauvinisme excessif tout en se présentant comme une vision réaliste de la guerre. On peut observer ici que ce qui se joue sur la scène des théâtres est tout à fait en phase avec le phénomène de librairie que représente la publication massive de journaux et de récits de guerre à partir de 1916. Le public est en fait à la recherche d'une représentation réaliste de la guerre et d'une figure à laquelle il peut s'identifier ou reconnaître ses proches au front. Cette pièce trahit de fait une mutation plus large de l'image du héros qui devient le soldat ordinaire, lui-même incarnation de la nation toute entière. De fait, elle est bien la traduction autant de la lassitude de la guerre que 
de la fatigue vis-à-vis de certaines formes éculées de la représentation de la guerre, donc d'une mutation du patriotisme et non de sa disparition.

La dernière partie de l'ouvrage est, elle, consacrée au théâtre aux armées. L'auteur montre que les pièces qui remportent le plus de succès sont celles qui offrent une distraction aux combattants par rapport à la réalité du front que ce soit par l'humour, la chanson, la revue, le cabaret. Les pièces dans lesquelles la frontière entre acteurs et spectateurs tendaient à s'estomper, soit parce que des combattants ou des gens de théâtres sous l'uniforme écrivaient, mettaient en scène et jouaient les pièces, soit parce que le public participait pleinement au spectacle, remportaient également un grand succès. En revanche, les pièces ressenties comme étant trop explicitement de la propagande en direction des soldats ou encore des populations occupées rencontraient moins l'adhésion. Un peu comme à l'intérieur du pays finalement, le message patriotique était d'autant mieux accepté qu'il semblait émaner d'en bas et non des autorités constituées. De fait, cette étude montre aussi que, le plus souvent, le rire au théâtre - omniprésent dans les spectacles qui remportent le plus de succès - aussi bien au front qu'à l'arrière - était plus une soupape permettant de tenir et de supporter la guerre que le résultat d'une satire politique dirigée contre ceux qui pourraient être jugés responsables de cette situation. On y retrouve d'une certaine manière une expression de cet Eigensinn si ambigu, cher à l'école allemande de l'histoire du quotidien.

On l'aura compris, le livre pionnier - qui donc appelle des comparaisons avec les autres pays en guerre - de M.B. est d'une réelle richesse. Il s'inscrit parfaitement dans de mouvement international de renouvellement de l'histoire de la Grande Guerre par le prisme culturel en ce qu'il explore l'inscription d'un art à la charnière entre la « culture de masse " et celle des élites dans son époque. En mettant finement en évidence les points communs et les différences entre le théâtre de l'avant et celui de l'arrière tout comme les circulations des représentations - dans les deux sens du terme - mais aussi les coupures entre des deux univers, le travail de M. B. montre que la notion de " culture de guerre » n'est en rien périmée et qu'employée avec précision, acuité, finesse et sans esprit de polémique, elle peut toujours féconder l'histoire de la Grande Guerre.

Nicolas Beaupré (Université Blaise Pascal - Clermont-Ferrand II) 